\title{
The Research on Teachers' Professional Development in the View of Organizational Identification
}

\author{
Jia Zhang \\ Education dep. Chengdu Normal University \\ Chengdu, Sichuan, China
}

\begin{abstract}
The characteristics of young teacher in basic education have determined that their organization is not high which has influenced their professional development. To properly introduce young teachers and carry out the socialization of the organization, improve the decision-making in democratic, strengthen the support and create the harmonious communication atmosphere in organization would be definitely the important ways to enhance the enthusiasm of the young teachers.
\end{abstract}

Keywords-young teacher; basic education; organazation identification

\section{INTRODUCTION}

Identification means the emotional relation in psychology. Organizational identification is a kind of psychology and behavior consistency by the individual and the organization. The members not only have the sense of contract and responsibility, but also the emotional belongings and dependence. Patchen(1975) once mentioned that organizational identification consists of three aspects : similarity , membership and loyalty. Chenney(1983) defines the organizational identification is a conformity process in which a person connected to the social scene .He thought it would be helpful to cultivate individual's sense of value, belonging and control.

The Antecedents of organizational identification consists of reputation, atmosphere, uniqueness, culture, including organizational factors and individual factors. The outcomes has the aspects of citizenship, job satisfaction, quit intention, cooperation intention etc. A large number of studies have shown that organizational identity can significantly affect the behavior of citizens, improve the job satisfaction, and negatively correlated to quit intention. The strength of organizational identity will have a significant impact on internal cooperation.

The Primary and secondary school teachers are backbone of the basic education development, but they are also the most unstable ones. Soon after they enter the workplace, they unusually have low salary and encounter the problems of professional development, which easily caused their confusion and unsatisfaction. The theory of organizational identification gives a new view of such Practical problems, emphasizes on

Sponsors:The Research Base of Humanities and Social Science in Sichuan Education Department(16SB0276); The Research Base of Sichuan Teacher's Professional Development (PDTR2016-010). the positive or negative feelings of members, and decides their actions.

\section{THE CHARACTERISTICS AND PROBLEMS OF YOUNG TEACHERS IN PRIMARY AND SECONDARY SCHOOLS IN ORGANIZATIONAL IDENTITY}

\section{A. The Young Teacher Who Got Less Suppot of the Organization Would Have Low Identification}

In this article, the definition of the young teacher are the ones who are above 40 years old. From the "Tablet I", we can see the change of the young teachers in primary school from 2003-2015. In those years, the number of young teacher is always maintains $60 \%$ ratio.

TABLE I. The Age Structure of Full-Time TeACHER IN PRIMARY SCHOOL FROM 2003 TO 2015

\begin{tabular}{|c|l|l|l|l|l|}
\hline Year & $\begin{array}{c}\text { Full-time } \\
\text { teacher } \\
\text { (person) }\end{array}$ & $\begin{array}{c}\text { Above } \\
\text { 30 years } \\
\text { old } \\
\text { (person) }\end{array}$ & $\begin{array}{c}\text { 31-35years } \\
\text { old and } \\
\text { above } \\
\text { (person) }\end{array}$ & $\begin{array}{c}\text { 36-40 } \\
\text { years } \\
\text { old and } \\
\text { above } \\
\text { (person) }\end{array}$ & $\begin{array}{c}\text { Ration of } \\
\text { full-time } \\
\text { teacher }\end{array}$ \\
\hline $\mathbf{2 0 0 3}$ & 5702750 & 1885385 & 784258 & 721448 & $59.50 \%$ \\
\hline $\mathbf{2 0 0 4}$ & 5628860 & 1805012 & 802961 & 693011 & $58.60 \%$ \\
\hline $\mathbf{2 0 0 5}$ & 5592453 & 1735158 & 827291 & 691056 & $58.20 \%$ \\
\hline $\mathbf{2 0 0 6}$ & 5587557 & 1664138 & 849044 & 713110 & $57.70 \%$ \\
\hline $\mathbf{2 0 0 7}$ & 5612563 & 1590214 & 885742 & 744490 & $57.40 \%$ \\
\hline $\mathbf{2 0 0 8}$ & 5621938 & 1516319 & 923869 & 784365 & $57.40 \%$ \\
\hline $\mathbf{2 0 0 9}$ & 5633447 & 1424706 & 980438 & 811347 & $57.10 \%$ \\
\hline $\mathbf{2 0 1 0}$ & 5617091 & 1343076 & 1033312 & 836200 & $57.20 \%$ \\
\hline $\mathbf{2 0 1 1}$ & 5604861 & 1250773 & 1067896 & 858896 & $56.70 \%$ \\
\hline $\mathbf{2 0 1 2}$ & 5585476 & 1196743 & 1085611 & 886266 & $56.70 \%$ \\
\hline $\mathbf{2 0 1 3}$ & 5584644 & 1013089 & 1049492 & 961730 & $54.20 \%$ \\
\hline $\mathbf{2 0 1 4}$ & 5633906 & 1035910 & 995424 & 1016408 & $54.10 \%$ \\
\hline $\mathbf{2 0 1 5}$ & 5685118 & 1084494 & 947123 & 1059395 & $54.40 \%$ \\
\hline
\end{tabular}

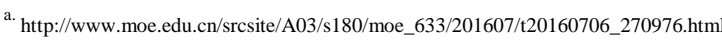

\section{B. The Divisity of Young Teachers Demand Leads to Different Identity}

According to young teacher's satisfactions, there are three kind of identification, survivability, success, and attribution. Regularly, the young teachers have the low salary because of the performance wage system, and the problem gets worse especially when they are about to get married, which easily causes the lower identification. The second aspect of their need is that the young teachers all hope to be accepted by the organization and obtain the success through their own efforts. The last aspect is the young teachers who have strong dedication and sense of mission. As the development of young 
teachers consistent with the development of the organization, it would greatly inspire the enthusiasm of young teachers, and they would produce strong belonging identity.

\section{The Defec of the Policy and Management Caused the Existence of Large Number of Substitute Teachers}

In reality, because of the authorized size of strength, many schools have a large number of substitute teacher, who are often the graduates just from the college. These parts of young teachers are the most unstable ones, who are paid by the school they served and usually be treated as the cheap labors. Their only way to become a authorized teacher is to pass a highly competitive recruit test. One research has shown that if a substitute teacher would turn to other career if they can't get the authorized identity after 3-5 years.

\section{Comparing to Other Age Groups, the Young Teachers Is the Most Unstable Groups and the Quit Rate Is always High}

Except for the substitute teachers we mentioned before, the young teacher group is the most unstable one in primary and elementary school. We take an example of a district in Sichuan and analyze the quit rate from 2000-2015. The results shows that there are 550 person quitting from their workplace, in whom 110 are retired, 14 are died, 5 are laid off and 421 are the quit ones.

The effect of Diminishing showed the young teachers will stabilize if they adapt to work circumstance. In fact, there exists a lot of problems causing the high quit, which also means they have the lowest identification to the organization. If young teacher with high liquidity characteristics meet the the limits of mechanism or system, flow tendency may become a reality. At the same time, the still-in young teachers can not be recognized as the completely strong identified group. They work in school for a long time for many reasons, including the loyalty of passive and active. Passive loyalty is forced by the limitation of development prospects and active loyalty refers to the young teachers will consciously to work hard for basic education cause, and shows more cooperative behavior. Passive loyalty will reduce organizational identification, eventually lead to the increase of the turnover intention. Organizational identity have a direct influence and significantly reduction on the tendency of quitting.

\section{The Strategy of CUltivating Young Teachers ORGANIZATIONAL IDENTIFICATION}

A large number of demonstration researches show that the factors affecting organizational identification includes socialization tactics, justice, support and communication, etc.

\section{A. Strengthen the School-based Training and Implement Strategies of Organizational Socialization}

The government should do the work of macro management, especially the regional talent planning. It would be better if the school has the power of personnel. The government should guarantee the talent plan to the development of the region and bring in the talents who are the school requires. The school should cultivate its own culture and goals, therefore, the new teachers can quickly adapt to the workplace, inspired by the culture and enhance their organizational identification.
When the new teacher entered the school, the school should combine the teachers' personal development to the development of the organization by fully considering the teaching and personal situation. So they can quickly integrated into the new environment and become the backbone. Every young teachers should experience the pre-job training, but there still problems under the existing mechanisms, such as training positioning error, Content blur and poor effect etc.

\section{B. Carrying Out the Socialization Strategy from the Perspective of Organizational Identification}

According to different individuals schools should arrange experienced teachers to lead the new teachers to integrated to cultural characteristics instead of getting together of the fixed training pattern. Firstly, the master teacher can lead the new teacher to find the practical way of how to teach the students, which can produce an immediate effect. The emotion they built can make the new teachers feel the fine tradition and quickly strengthen organizational identity. Secondly, pay attention to the level of the development of young teachers. Most of them have such problems as buying houses, getting married etc. Besides, they are energetic groups and always have a higher level of need. So it is better for the school to focus on the sustainability and the personalized of the young teacher. Thirdly, the school can break through the limitation of system to encourage and help the outstanding young teacher to grow to the backbone teachers. Fourthly, Professional Ethics is so important to the young teachers that the school should strengthen the education to the young teachers, who always be sensitive to the politics and policies. Fifthly, the education and school should try to treat everyone fairly. It contains three aspects, distributive, procedure and interactive justice. Distribution is a broad concept, which refers to specific salary bonuses, other benefits and kinds of spiritual encouragement, including various kinds of education opportunities and communication opportunities. The purpose of distribution is the maximize the combined personal development and organizational development, for teachers to realize self value and their aim. Procedure justice means the decisions and policies the school making should let the teachers feel the justice and public in procedure and methods. Interactive justice means the organization should consider the views of the young teachers as much as possible to improve the democracy of decision-making .

\section{Creat the Harmonious Communication Atmosphere and Increase the Participation of Young Teachers in Organizing Activities}

Young teachers are the group with the greatest potential, but they are also the most volatile group. Schools should care about the experience and ideas of young teachers. First, the income distribution policy transparent should be open and fair to let the young teachers to feel about the concern of the organization, which will bring the effect of value guide. Secondly, the policy of transparency, such as leadership appointments, awards etc, should enables young teachers to understand and support. Thirdly, to improve the organization's democracy.

Schools should communicate with young teachers in a time before making decisions, and it would increase the 
participation of young teachers. Communication is a common phenomenon in organizational management, and is essential to any organization's management. Education and school management department should create conditions to promote communication and exchanges between teachers and different stakeholders to enhance mutual understanding and mutual support. School leaders should create a top-down communication actively and harmonious atmosphere, thus improving teachers' organizational identity and mental health. In the process of the communication with young teachers, it's better to take two-way communication mode, which means the school organization and young teachers are able to express their ideas to achieve achieve, maximum mutual understanding and eliminating barriers of communication. These are beneficial to young teachers to improve organizational identification. Through communication, it is possible to find out the employment tendency and the emotional problems. Through communication, the policy can be more humanized, make young teacher's goals, including long-term and shortterm to combine with the school's development, and reduce the external factors' attraction. If the teachers have involved in the enriched recreational activities, their organization identity would definitely.

\section{Strengthen the Support of the Organization and Make the Young Teachers Feel the Concern and Support of the Organization}

Organization support refers to the ability of young teachers to receive organizational support and care in times of difficulty. We should care about the lives of young teachers and pay attention to the problems that young teachers attention most, and properly handle all kinds of conflict interests. Thoughtful care may have a better effect than simply raising salary to raise the organization of young teachers. Only when feel the positive support, will they gradually accept the culture and values, then, combine into a personal goal and value systems. Their identity and sense of belonging to the organization will be further strengthened.

\section{E. Attach Importance to the Reputation of Itself, Promote the Cultural Construction of the Organization, and Increase the Self-esteem and Social Acceptance of Young Teachers}

A school with rich culture and reputation excellence is the one who attracts young teachers's attention. Years of accumulation are the aspiration of young teachers. Organization reputation affects organizational identity, because the more people perceive reputation, the more likely it is going to gain self-esteem from approval. All the members would be so proud of belonging to the group and feel their social recognition when the organization has a good organization reputation, thus, it will improve the members of the organization. The negative events that affect the reputation of the school should also be eliminated in time. At the same time, pay attention to the ones who only treat their work as raising the family.

\section{CONCLUSION}

In summary, the young teachers are the cornerstone of the future development of basic education. This is an important part of school management to improve young teachers' organizational identification and integrated them into the school. This is the task that we need to continue to study. only rising organizational identification of young teachers, can the school have the continuous development itself, so as to promote the continuous development of higher education.

\section{REFERENCES}

[1] Cheney G. "On the Various and Changing Meanings of Organizational Membership: A Field Study of Organizational Identification": Communication Monographs, 1983, 50: 342 362.

[2] Ashforth B E, Mael F. Social identity theory and organization. Academy of Management Review, 1989, 14 (1) : 20 39.

[3] BargeJ K, Schlueter D W. A critical evaluation of organizational commitment and identification. Management Communication Quarterly. 1988, 2 (1) : 116 133.

[4] Shamir B, Kark R A. Single-item graphic scale for the measurement of organizational identification. Journal of Occupational and Organizational Psychology, 2004, 77: ,115 123.

[5] Dutton, J. E. , Dukerich, J. M. , \& H arqu ai,1 C. V. ( 1994 ). Organ izational im ages and $\mathrm{m}$ em ber ident ification. Adm in istrative Science Quarterly, 39,.239-263.

[6] J. Clerk Maxwell, A Treatise on Electricity and Magnetism, 3rd ed., vol. 2. Oxford: Clarendon, 1892, 68-73.

[7] Hall D T, Schneider B, Nygren H T. Personal factors in organizational identification. Administrative Science Quarterly. 1970, 15 (2) : 176-190

[8] Mael F A, Ashforth B E. Alumni and their alma Mather: a partial test of the reformulated model of organizational identification. Journal of Organizational Behavior, 1992, 13 (2) : 103-123.

[9] Meger J P, Becker T E, Dick R V. Social identities and commitments an work: toward an integrative model. Journal of Organizational Behavior, 2006, 27 (3) : 665-683.

[10] Carmeli A, Gilat G, Weisberg J. Perceived external prestige, organizational identification and affective commitment: a stakeholder approach. Corporate Reputation Review, 2006, 9 (2) : 92-104. 